\title{
GRACINO JUNIOR, Paulo. 2016. A demanda por deuses: globalização, fluxos religiosos e culturas locais nos dois lados do Atlântico. Rio de Janeiro: EdUERJ. 350 pp.
}

\author{
MICHELLE GONÇALVES RODRIGUES
}

Paisagens brasileiras e portuguesas compõem o diálogo estabelecido entre pentecostalismo protestante e catolicismo no livro de Paulo Gracino Junior. Observando o potencial das abordagens socioantropológicas em compreender a resistência de algumas regiões à penetração e investida das igrejas pentecostais, o autor nos conduz, em trechos bem humorados, por um caminho ainda pouco elucidado em que a cultura se alia à tradição para inibir o avanço do pentecostalismo. Assim, ao invés dos "efeitos solventes e destradicionalizantes da cultura" (:22) provocados pelo pentecostalismo, "A demanda por deuses: globalização, fluxos religiosos e culturas locais nos dois lados do Atlântico" percorre contextos que se mostram inibidores deste movimento. Na obra apresentada pelo autor, a região histórica de Minas Gerais e a região do Porto aparecem como aquelas em que o ethos católico está intimamente ligado não apenas à pertença religiosa de seus moradores, mas permeiam as identidades locais daqueles territórios para além dos fiéis. Analisando dados censitários e de estudos realizados por outros pesquisadores, percorrendo arquivos e alçando a história oral como meio de acesso aos sentidos da realidade, a obra se caracteriza como uma pesquisa comparativa complexa e desafiadora que vem contribuir para o debate no campo dos estudos sobre religião.

A abordagem escolhida, além de inverter as anteriores, possibilita problematizar a apropriação feita pela sociologia da religião do paradigma da escolha racional. Em outras palavras, a religião se torna uma metonímia para as relações sociais, como indica Gracino Junior. Isto porque, o trânsito religioso não é denominado pela escolha racional, aos moldes da teoria econômica, mas sua realização se dá por relações societais que mobilizam aspectos objetivos e subjetivos. Dessa maneira, elementos socioculturais se combinam aos aspectos peculiares das escolhas individuais não somente para o trânsito religioso dos sujeitos em nível local, mas, também, para a interação entre fluxos religiosos globais e culturas locais. Estamos frente ao processo de globalização, entendido pelo autor como a percepção aguda do grau de interdependência em que vivem diversos países do mundo, para além da simples visão desta interdependência nos planos político e econômico. Tal compreensão implica no jogo promovido pelas noções de global e local quando se observa a promoção das diferenças e diversidades no nível das 
culturas locais. Entre fluxos globais e culturas locais, a religião se combina à identidade, fazendo com que em certos contextos a investida pentecostal tenha êxito e em outros seja rechaçada.

No mundo globalizado as grandes narrativas foram postas à prova por sociedades cada vez mais plurais. Disso as instituições se veem na necessidade de se readequarem às demandas oriundas dos meios socioculturais, inclusive as instituições religiosas, tendo em vista que ampla parcela das pessoas se define como crente em alguma religião. Assumindo a perspectiva de Niklas Luhmann, Gracino Junior considera que a religião estabelece "uma reserva de sentido que dá ao sistema social maior capacidade de tolerar o aumento da indeterminação" (:34).

Se antes o catolicismo aparecia hegemônico, nesta nova configuração outras formas religiosas surgem e se expandem, como as várias denominações pentecostais. Entretanto, todas estas formas religiosas, não podendo flexibilizar seus conteúdos teológicos sem um limite definido, acabam por atender a demandas pontuais que estão diluídas em pequenos grupos. $\mathrm{O}$ resultado deste quadro é o fenômeno do trânsito religioso, que acompanha a pluralidade religiosa. Um fenômeno próprio do mundo globalizado, em que a Igreja Católica perdeu sua capacidade de unificar anseios encontrados na sociedade. Neste cenário, entre pentecostalismo e catolicismo, o último tende a encontrar maiores dificuldades de acomodação devido à sua estrutura hierárquica e ritual. Para o caso brasileiro, o autor indica que, a partir dos dados do Censo de 2010, a religião católica é predominante em alguns contextos, como nas áreas mais tradicionais e menos dinâmicas. Ao passo que o pentecostalismo tem maior entrada nas regiões periféricas e nas áreas de fronteira e de recepção de imigrantes. Esta distribuição sugere, ainda de acordo com o autor, ao elencar as ideias de Cecília Mariz e John Burdick, que o pentecostalismo, por possuir um aparato institucional-litúrgico mais próximo aos desejos das pessoas, consegue traduzir as demandas para o discurso religioso.

Passando por movimentos que envolvem memória e patrimonialização, o catolicismo se ampara pelas identidades e culturas locais, que são fortalecidas, inclusive, por meio do turismo e sua característica mercadológica. Tais formas regionais de cultura são encontradas não só no Brasil, mas também em Portugal, especificamente em seu território do norte. Todo esse quadro contrapõe, assim, a ideia de que os fluxos religiosos perderiam sua força num mundo secularizado, marcado por escolhas racionais. Para o desenvolvimento do enredo narrado, o livro está estruturado em cinco capítulos, que se distribuem em três partes.

No Capítulo I duas dinâmicas complementares são empreendidas. Uma crítica ao processo de secularização como destino para as sociedades na modernidade, abrangendo as sociedades avançadas e as subalternas. Estas últimas, arrancadas desta característica "por meio do estabelecimento de um estado laico fundamentado na razão" (:59). Em outros termos, a conversão do conceito de secularização em paradigma é questionada por Gracino Junior quando o autor observa que mesmo diante das críticas estabelecidas por pesquisadores anteriores, ao evidenciarem a relação da religião com processos externos a este campo - como a globalização -, o conceito não deixou os ares de paradigma ao fomentar novas interpretações sobre o momento contemporâneo. A segunda dinâmica, a partir da crítica estabelecida, coloca em relevo como as teorias econômicas e da escolha racional substituíram o conceito de secularização. Ou seja, se a religião não foi inviabilizada pela racionalidade moderna sua adesão ocor- 
re atrelada à ideia de escolha racional. Uma escolha realizada num cenário de mercado religioso que congrega diversos tipos religiosos em disputa por fiéis. Por seu turno, estes fiéis têm a possibilidade de escolher o melhor tipo para a sua adesão, uma adesão feita a partir de interesses e, por isso, não estática. Disso, o trânsito religioso é compreendido como uma das marcas da religião na modernidade.

Se a modernidade apresenta uma complexidade de entendimento quanto às várias demandas requeridas pelos sujeitos sociais, Gracino Junior traz as proposições de Luhmann para elencar a religião como aquela que confere sentido último à existência. Pois, a principal função religiosa é sua hermenêutica que tem a potencialidade de assegurar sentido a uma realidade progressivamente fragmentada. Aqui, pode-se tecer um elogio ao apuramento teórico adotado pelo autor, tendo em vista que a sociologia da religião geralmente tende em assumir o conceito de secularização weberiano sem o olhar compreensivo do alemão. Já que enquanto Max Weber se preocupou em observar as mudanças provocadas pela modernidade a partir da religião, nossa sociologia tendeu a observar uma certa idiossincrasia entre religião e modernidade. Daí o paradigma da secularização como destino - e de sua proximidade com a ideia de escolha racional -, um destino que hoje sublinha o assombro da retomada religiosa no mundo ocidental e, no caso brasileiro, um destino que, para muitas interpretações, definiu nossa não racionalidade moderna quando voltamos àquelas abordagens que nos viam como uma sociedade nascida do catolicismo popular e mágico.

Voltando aos escritos de Gracino Junior, a modernidade é marcada por demandas imediatas. Disso as grandes narrativas perdem seu lugar central de explicação, enquanto outras narrativas de curto prazo surgem. Estas narrativas são obrigadas, então, a disputar a tradução dos problemas seculares e imediatos em discursos teológicos. Estamos diante de um pluralismo religioso que se faz por meio de escolhas elaboradas em processos de socialização e não, simplesmente, por escolhas racionais de interesses. Observação que desautoriza as teorias econômicas e da escolha racional para a compreensão dos fluxos religiosos, tendo em vista que tais teorias implicam no compromisso assumido com um ideal a ser conquistado, algo bem diverso do pluralismo religioso encontrado na realidade social.

É deste pluralismo religioso em Portugal e no Brasil, respectivamente, que os Capítulos II e III tratam, capítulos que compõem a Parte II da obra. Para além da região Norte do Porto e da região histórica de Minas Gerais, os dois países têm seu pluralismo demonstrado. Com dados históricos e censitários, diversos tipos religiosos, assim como as categorias sem religião, são tratados na configuração das duas nações. Além de problematizações quanto às definições censitárias, que trazem ruídos para a interpretação dos campos religiosos, o estudo comparativo proposto busca entender, de maneira um tanto polêmica, os processos de imigração e emigração presentes naquelas realidades e no que implicam para as configurações religiosas atuais. Tudo isso relacionado às características econômicas e de classe das populações que estão divididas entre centro e periferia, tanto sob a forma de metrópoles e cidades menores, como para a divisão encontrada em uma mesma cidade. Realçar estas separações, que aparecem também por dicotomias, possibilita a demonstração de como os problemas, anseios e demandas são traduzidas num discurso teológico pelas religiões. Uma tradução que implica pensar, novamente, com Lumann e sua teoria dos subsistemas, que a relação entre religião e identidade perpassa noções de legitimidade, confiança. 
Da demonstração dos campos religiosos português e brasileiro, os Capítulos IV e V trazem, nesta ordem, os estudos de caso da região Norte de Portugal e a da região histórica de Minas Gerais. Regiões entendidas como tradicionais, pouco dinâmicas e refratárias ao crescimento pentecostal. Para o primeiro caso, um antigo cinema desativado na cidade do Porto, o "Coliseu do Porto", aparece como o mote que relaciona religião, cultura e identidade local. Em uma tentativa de compra deste espaço pela Igreja Universal do Reino de Deus (IURD) nasce o movimento de rechaço “O Coliseu é nosso!”. Neste ponto outros aspectos permeiam a história, que se passou no ano de 1995, como a União Europeia e o processo de europeização sofrido por Portugal, e o movimento turístico na região, principalmente por meio das festividades religiosas católicas. Também ganha destaque na história o estereótipo brasileiro em terras portuguesas e a recusa da brasilidade na tradicional região do Porto. Uma região que, ao relembrarmos o passado ibérico, foi o cenário, não tão tradicional, de uma revolução liberal que conseguiu se espalhar por todo Portugal. Talvez deste passado, fundado na noção de liberdade, o movimento "O Coliseu é nosso!" possa também ser compreendido.

Em Minas Gerais, o município de Mariana, primeira capital do estado nos tempos das capitanias brasileiras, é o cenário das observações do autor. Acompanhando sua história e do catolicismo ali estabelecido, principalmente na cativante descrição da sexta-feira da Semana Santa, momento de grande relevância turística para Mariana, a mineiridade aparece como categoria analítica de explicação para o não avanço pentecostal naquele espaço. Isto porque, "romper com o catolicismo [...] seria romper com a origem, romper com a mineiridade, reorganizar a vida a partir de novas narrativas, [...] possibilidade que se mostra bastante improvável nesses contextos regulamentados por sólidas identidades grupais" (:280). Assim, o contexto identitário inibe o crescimento das igrejas pentecostais nas cidades históricas mineiras, sendo o catolicismo, com suas festas religiosas, um patrimônio cultural da barroca Minas Gerais. Um tradicionalismo cultural, identitário e de memória atemporal, que aparece na forma de relações sociais permeadas por rupturas segmentárias, dando sentido à fragmentação da vida promovida pela modernidade. Desta identidade encenada pela Semana Santa está uma identidade que comove e agrupa ao mesmo tempo em que regula outras escolhas religiosas e o trânsito religioso naquele contexto. Pois, na mineiridade da memória atemporal das identidades locais e históricas, até mesmo os que se convertem ao pentecostalismo têm de lidar com a devoção aos santos. Neste ponto, porventura seja o barroco do catolicismo popular não apenas como um estilo artístico, mas, fundamentalmente, uma maneira da mineiridade de significar a vida e sua existência.

Finalmente, cabe dizer que o livro de Gracino Junior não é apenas fruto de uma pesquisa de fôlego, mas uma obra que permite um provocativo e intenso diálogo sociológico, antropológico e até mesmo histórico para a compreensão da realidade social, de forma a possibilitar uma sociologia compreensiva sobre a religião e sua importância na interface com outros subsistemas nas interpretações preocupadas com a modernidade em tempos de globalização. 
Michelle Gonçalves Rodrigues é doutora em Antropologia pelo PPGA/UFPE. compós-doutorado em Ciência Politica na Universidade Federal de Juiz de Fora (UFJF), e professora do Departamento de Ciências Humanas da Universidade do Estado de Minas Gerais.

RECEBIDO: $10 / 03 / 2017$

APROVAO: $27 / 11 / 2017$ 
264 CAMPOS v.18(1-2), 2017 